\title{
Evaluation and Identification of Basil Germ Plasm for Resistance to Fusarium oxysporum f. sp. basilicum
}

\author{
Reuven Reuveni, Nativ Dudai, and Eli Putievsky, ARO, Newe Ya'ar Research Center, P.O. Box 1021, Ramat \\ Yishay 30095, Israel; W. H. Elmer, The Connecticut Agricultural Experiment Station, New Haven; and R. L. \\ Wick, The University of Massachusetts, Amherst
}

\begin{abstract}
Reuveni, R., Dudai, N., Putievsky, E., Elmer, W. H., and Wick, R. L. 1997. Evaluation and identification of basil germ plasm for resistance to Fusarium oxysporum f. sp. basilicum. Plant Dis. 81:1077-1081.

Growth chamber evaluation of several cultivars of basil and related herbs examined in the United States revealed that identical cultivars from different sources did not differ in their reactions to artificial inoculation with Fusarium oxysporum f. sp. basilicum. Cultivars differed in susceptibility to the pathogen: "Spicy globe" miniature was the most susceptible, and lemon basil (Ocimum basilicum var. citriodorum), Origanum majorana, and Thymus vulgaris were rated as not susceptible. Twenty isolates of $F$. oxysporum, originating from stems of diseased basil plants in Israel, were pathogenic on basil in growth chamber and greenhouse tests. Under artificial inoculation, 2 isolates of $F$. oxysporum f. sp. basilicum from stems were pathogenic to basil but not to 9 species representing Lamiaceae, Cucurbitaceae, Solanaceae, and Compositae, indicating the specificity of the pathogen to basil. These isolates were used for additional resistance tests. Ocimum basilicum var. purpurascens (Exotic) and var. citriodorum were rated as not susceptible to the pathogen under artificial inoculation. Resistant germ plasm was identified in several basil plants of a local variety originally introduced from the United States and reselected at Newe Ya'ar. Seeds were planted in the greenhouse in naturally highly infested soil. Symptomless plants that survived in naturally infested soil were the source for F1 seeds of resistant germ plasm, which was confirmed by artificial inoculations with both isolates of the pathogen. Further selection tests to improve resistance were conducted up to the F4 generation in infested soil in the greenhouse. All individuals of the present genetic line remained symptomless, while all individual plants of the original susceptible cultivar defoliated 3 weeks after planting into infested soil, suggesting that the resistance may be a single, dominant gene. The causal organism was reisolated only from the susceptible plants and not from the symptomless resistant plants through all the experiments.
\end{abstract}

Sweet basil (Ocimum basilicum L.) is a cultivated fresh herb grown commercially in the United States and in the Mediterranean region. It has become popular in the last 10 years and is used, both fresh and dried, as a food spice and in traditional medicine. Fusarium wilt of basil is a destructive disease caused by Fusarium oxysporum f. sp. basilicum. The disease causes stunting of the plant, browning of the vascular tissue, and premature defoliation. Although the disease has been known since 1956 (12) and occurs in Russia, Italy (6), and France (8), it recently appeared in numerous states in the United States $(2,4,13)$ and in Israel $(5,9)$. Seed transmission is believed to be the principal means

Corresponding author: R. Reuveni

E-mail: vfnrreuv@volcani.agri.gov.il

Contribution from the Agricultural Research Organization, The Volcani Center, Bet Dagan, Israel. No. 1887-E, 1996 series.

Accepted for publication 27 May 1997.

Publication no. D-1997-0728-02R

(C) 1997 The American Phytopathological Society of dissemination (4). The expansion of cultivated areas of sweet basil in the United States and Israel has been accompanied by a corresponding increase in the disease, which limits the production of this valuable crop. The unavailability of commercially acceptable resistant cultivars dictates the need for identification of resistant germ plasm for breeding purposes.

The host range of this disease has been reported to extend to sweet and lemon basil cultivars, whereas 6 other herbs in the family Lamiaceae were reported to be immune (7). However, there is a need to examine a wider selection of cultivars to determine if there are any resistant cultivars in Ocimum basilicum.

It was also noted in field trials with a single standard bush variety of sweet basil that plants grown in infested soils varied widely in their reaction to Fusarium wilt: some plants appeared unaffected, while adjacent plants in the same plot were badly stunted and near death (4). The same observation also was made in Israel (10), indicating that there was a possibility to select resistance to Fusarium wilt from the progeny of commercially available and horticulturally acceptable germ plasm.
The objectives of the present investigation were to evaluate several cultivars of basil and related herbs, for their resistance to Fusarium wilt, to confirm the pathogenicity and determine the specificity of $F$. oxysporum f. sp. basilicum isolates from Israel, and to identify and select resistant germ plasm of basil which exhibited resistance to Fusarium wilt. Studies were conducted at three locations: Newe Ya'ar Research Center, Haifa, Israel; the University of Massachusetts, Amherst; and the Connecticut Agricultural Experiment Station, New Haven.

\section{MATERIALS AND METHODS}

Evaluation of cultivars of basil and related herbs (United States): plants and inoculum. Seeds of various cultivars of basil and related herbs species were obtained by the Connecticut Agricultural Experimental Station from commercial seed companies (Table 1). Seeds were germinated in potting mix (peat:vermic ulite, 1:1) and healthy transplants, 7 to 10 $\mathrm{cm}$ tall, were used in tests. A highly virulent isolate of $F$. oxysporum f. sp. basilicum (MA48, Fusarium Research Center accession Number 0-1042) was grown on potato dextrose agar plates for 7 to 10 days at $25^{\circ} \mathrm{C}$ in the dark (3). Inoculum was prepared by washing plates with sterile distilled water and passing the contents through sterile cheesecloth to remove mycelial fragments. Conidia (almost exclusively microconidia) were diluted to a concentration of $1 \times 10^{6}$ conidia $/ \mathrm{ml}$. One transplant of each cultivar was placed into 10-cm-diameter plastic pots filled with potting mix. Five pots of each cultivar were treated 10 days later with the conidial suspension by injecting $10 \mathrm{ml}$ to a $2-\mathrm{cm}$ depth in the root zone, approximately $2 \mathrm{~cm}$ on each side of the stem. An equal number of pots were injected with distilled water to serve as controls. Plants were set in a growth chamber equipped with cool white fluorescent tubes $\left(450 \mu \mathrm{E} / \mathrm{m}^{2} / \mathrm{s}\right)$ at a $12-\mathrm{hr}$ photoperiod at $25^{\circ} \mathrm{C}$. After 4 weeks, fresh and dry weights of the plant above ground were recorded. The percentage reduction in dry weight was determined by the formula: [(healthy dry weight - diseased dry weight)/healthy dry weight] $\times 100$. The experiment was repeated once.

Specificity of the pathogen, identification of resistant germ plasm of basil in Israel, and selection of resistant prog- 
eny: isolation and pathogenicity of the isolates. Seeds of a local commercial basil variety "Newe Ya' ar" (NY) received originally from the United States (Seed Set Co., CA) were planted in naturally infested soil in the greenhouse at Newe Ya'ar Research Center. Stem segments of several basil plants with characteristic symptoms of Fusarium wilt were surface-disinfested in $0.5 \% \mathrm{NaOCl}$ for $60 \mathrm{~s}$, and placed on potato dextrose agar. Twenty pathogenic isolates of $F$. oxysporum were obtained, identified microscopically, and used for studies on pathogenicity and specificity. Practically, 2 isolates of the fungus, designated FUS-1 and FUS-3, which had been recovered from stems of symptomatic plants, were grown on potato dextrose agar for 10 days at $25^{\circ} \mathrm{C}$ in the dark. Inoculum was prepared by gently brushing plates with sterile through cheesecloth to remove mycelial fragments. The resulting suspension was then diluted to obtain $5 \times 10^{5}$ conidia $/ \mathrm{ml}$. Ten transplants at the five-leaf stage were distilled water, which was then passed

used to confirm pathogenicity of each isolate; each of them was dipped in the conidial suspension to enable $10 \mathrm{ml}$ of the inoculum suspension to soak into the media (peat:vermiculite, 1:1) of the developed roots, which were subsequently planted in pots filled with $500 \mathrm{~g}$ of noninfested soil. Inoculated and control plants were incubated in the greenhouse with an $18 / 30^{\circ} \mathrm{C}$ night/day temperature regime for symptom development. An equal number of transplants were dipped in water and placed in pots to serve as controls. Reisolation tests of the causal organism were conducted through all experiments.

Relation between soil infestation and pathogenicity. To confirm pathogenicity of the soil, 5 seeds of the variety NY of the flat leaves var. basilicum (accession NY B SW, Swiss basil) were planted in each of 10 pots containing $500 \mathrm{~g}$ of each of the following soils: local noninfested soil as control (C); naturally infested soil (NI); and naturally infested soil which had been autoclaved for $30 \mathrm{~min}(\mathrm{NI}+\mathrm{AU})$.

Table 1. Sources of basil cultivars and related herbs, and their reaction to Fusarium oxysporum f. sp. basilicum

\begin{tabular}{lrcc}
\hline Species & Cultivar & Source $^{\mathbf{a}}$ & Percent dry weight reduction $^{\mathbf{b}}$ \\
\hline Ocimum basilicum & Anise & SG & 43 \\
& Cinnamon & SG & 40 \\
& Cinnamon & CG & 37 \\
& Fino Verde 'Piccolo' & CG & 45 \\
& Fino Verde 'Piccolo' & SG & 47 \\
& Greek Mini & SG & 17 \\
& Mammoth & CG & 40 \\
& Green broadleaf & SG & 26 \\
& Napoletano & SG & 31 \\
& Opal & CG & 27 \\
& Perfume & SG & 29 \\
& Purple Ruffles & SG & 20 \\
O. basilicum var. crispum & Purple Opal & SG & 43 \\
O. basilicum "citriodorum" & Spicy Globe miniature & SG & 65 \\
Origanum majorana & Sweet Genovese & CG & 20 \\
Thymus vulgaris & Lettuce Leaf & SG & 37 \\
& Lemon Basil & SG & 20 \\
Lemon Basil & CG & 31 \\
& Sweet marjoram & CG & 7 \\
& Thyme de Provence & CG & 8
\end{tabular}

${ }^{\mathrm{a}}$ CG $=$ Cooks Garden Seed Co., Londonderry, VT; SG = Shepherds Garden Seeds, Torrington, CT.

${ }^{b}$ Values represent the mean differences in dry weights [(uninoculated - inoculated)/uninoculated] from two separate trials (5 replicates per trial).
The pots were then incubated in the greenhouse with a $18 / 30^{\circ} \mathrm{C}$ night/day temperature regime for symptom development.

Test of specificity of the causal organism to basil plants. Seeds of NY variety and those of the species Mentha piperita, Micromeria fruticosa, Lavendula officinalis (Lamiaceae), Lycopersicon esculentum, Capsicum annuum (Solanaceae), Cucumis sativus (Cucurbitaceae), and Artemisia dracunculus (Compositae) were germinated in potting mix (peat:vermiculite 1:1), and at the five-leaf stage were inoculated as described above. After inoculation, plants were transferred to pots containing $500 \mathrm{~g}$ of noninfested soil. Non-inoculated transplants were used as controls and placed with the inoculated transplants in the greenhouse for symptom development.

Identification of resistant germ plasm and selection of resistant progeny. Although most of the NY plants in the abovementioned naturally infested soil died, several symptomless plants were selected, covered with an insect-proof net to enable self-pollination, and used for the production of seeds of the F1 population. Basil seeds of the susceptible NY variety and those of F1 resistant plants, $O$. basilicum var. basilicum (Swiss basil), var. purpurascens (accession NY B 74, Exotic) and var. citriodorum were planted in potting mixture and grown in the greenhouse. Ten plants (five-leaf stage) of each population were inoculated with isolates FUS-1 and FUS-3 as described above and then transplanted into pots containing $500 \mathrm{~g}$ of the following soils: autoclaved or non-autoclaved naturally infested soil, and autoclaved or non-autoclaved non-infested soil. Inoculated and control plants were incubated in the greenhouse with a $18 / 30^{\circ} \mathrm{C}$ night/day temperature regime for symptom development. An equal number of transplants were dipped in water and placed in pots containing non-infested (non-autoclaved) soil to serve as controls. The number of defoliated plants was recorded for each progeny.

Immediately after disease evaluation, the above-ground parts of the plants were re-

Table 2. Reaction of basil varieties and breeding line F1 to artificial inoculation with Fusarium oxysporum f. sp. basilicum

\begin{tabular}{|c|c|c|c|c|c|}
\hline \multirow[b]{4}{*}{ Variety } & \multicolumn{5}{|c|}{ Number of defoliated plants ${ }^{a}$} \\
\hline & \multirow[b]{3}{*}{ Control $^{b}$} & \multicolumn{4}{|c|}{ Inoculated } \\
\hline & & \multicolumn{2}{|c|}{ Non-autoclaved } & \multicolumn{2}{|c|}{ Autoclaved } \\
\hline & & FUS-1 & FUS-3 & FUS-1 & FUS-3 \\
\hline NY (S) & 0 & 3 & 8 & 10 & 9 \\
\hline $\mathrm{F} 1(\mathrm{R})$ & 0 & 2 & 4 & 6 & 10 \\
\hline Ocimum basilicum cv. Swiss & 0 & 0 & 1 & 3 & 9 \\
\hline O. basilicum cv. Exotic & 0 & 1 & 0 & 0 & 0 \\
\hline O. basilicum "citriodorum" & 0 & 0 & 0 & 0 & 0 \\
\hline
\end{tabular}


moved and additional seeds from the same sources were planted in the same pots, to screen plants at a higher inoculum density; this provided a better selection for resistance among the F1 population. Seeds were collected as described above, but only from surviving symptomless plants, to obtain F2 populations. Basil seedlings at the fourleaf-stage of the following populationscommercial (NY) variety, resistant F1, resistant $\mathrm{F} 2$ (derived from $\mathrm{F} 1 \times \mathrm{F} 1$ crosses), and $\mathrm{F} 3$ populations derived from self crosses of plants resistant to FUS-1 (F3-Selec-1) or to FUS-3 (F3-Selec3)-were inoculated by root-dipping with microconidia of 2 isolates of $F$. oxysporum, as described above. This was to obtain further confirmation of their resistance against the pathogen. The seeds of F3 populations were collected from resistant plants after self-crosses. Subsequent selections for resistance were made on F3 populations under artificial inoculation with a mixture of equal number of microconidia of both isolates (FUS-1 and FUS3).

Resistance expression of basil breeding lines under naturally infested soil was tested by planting (at spring) seeds of the susceptible NY variety and of the resistant $\mathrm{F} 1$ and $\mathrm{F} 2$ progenies in the greenhouse on naturally infested soil and marked as $\mathrm{R}=$ Resistant F1 or F2, or $\mathrm{S}=$ Susceptible Newe Ya'ar variety.

Symptom development was rated on each plant using a 0 to $100 \%$ scale as follows: $0=$ no symptoms, $25 \%=$ slight stunting or wilt, $50 \%=$ severe wilting and stunting ; and $100 \%=$ defoliation. The mean number at each level was recorded and calculated for each progeny, and disease incidence was expressed as the sum of all mean values for each progeny.

\section{RESULTS}

Evaluation of cultivars of basil and related herbs (United States). All basil cultivars examined in the growth chamber were considered susceptible to Fusarium wilt. However, various levels in reduction of plant dry weights were recorded. Plant dry weights were reduced by 17 to $65 \%$ compared with controls (Table 1). Identical cultivars from different sources did not differ in their reaction to Fusarium wilt, but different cultivars differed in susceptibility. "Spicy Globe" miniature was affected the most with a mean $65 \%$ reduction, whereas "Greek Mini" was the most tolerant and was reduced by only $17 \%$. The lemon basil cultivar $(O$. basilicum var. citriodorum) had reduced dry weight, but did not show wilt symptoms. Origanum majorana "Sweet marjoram" and Thymus vulgaris "Thyme de Provence" had only slight reductions in dry weight and were rated as not susceptible to $F$. oxysporum $\mathrm{f}$. sp. basilicum.

Specificity of the pathogen, identification of resistant germ plasm of basil in
Israel, and selection of resistant progenies. Among 20 isolates of $F$. oxysporum which originated from stems of diseased basil, only two (FUS-1 and FUS-3) were pathogenic and caused defoliation of all tested plants of the local susceptible cultivar (NY) within 3 weeks after inoculation. Both isolate FUS-1 and FUS-3 were recovered from stem segments of all inoculated plants.

All plants of both NY and Swiss basil cultivars remained symptomless in autoclaved soil regardless of infestation of the soil. In addition, Swiss basil had a lower incidence of Fusarium wilt in non-autoclaved infested soil as compared with NY cultivar.

Specificity of the pathogen to sweet basil was determined by means of artificial inoculation of 9 species conducted in the greenhouse. Two stem-originated isolates of $F$. oxysporum were pathogenic and caused defoliation of all tested NY basil plants but had no effect on nine species, including Mentha piperita, Micromeria fruticosa, Lavendula officinalis (Lamiaceae), Lycopersicon esculentum, Capsicum annuum (Solanaceae), Cucumis sativus (Cucurbitaceae), and Artemisia dracunculus (Compositae).

Identification of resistant germ plasm. Based on the numbers of defoliated plants among several cultivars and lines, resistant germ plasm is evident in selected population F1 derived from a self-cross of NY basil, and also in other varieties (Table 2).
All basil varieties remained symptomless in the control non-autoclaved or autoclaved soil. The resistant reaction was apparent and was expressed in F1 (R) as a mean of $70 \%$ healthy plants, compared with $45 \%$ symptomless plants of the NY variety in non-autoclaved soil. In autoclaved soil $20 \%$ of the F1 (R) and only $5 \%$ of NY plants remained symptomless. For NY and Swiss basil varieties, both isolates of the pathogen were more virulent in autoclaved soil than in non-autoclaved soil. Disease incidence on NY, Swiss basil, and selected populations of resistant F1, F2, and F3 breeding lines was rated after artificial inoculation with $F$. oxysporum (FUS-3; Fig. 1). Swiss basil had high disease incidence, and all plants of the NY variety died at 24 days after inoculation. However, F1 plants had low disease incidence, and all F3 plants remained symptomless and healthy. The causal organism was reisolated only from the symptoms-bearing plants, but from none of the symptomless resistant plants.

Resistance of the selected progenies was confirmed in the original naturally infested soil at Newe Ya'ar. All plants of the NY variety died, whereas plants of F1 and F2 remained symptomless (Fig. 2).

\section{DISCUSSION}

Fusarium wilt of basil is destructive and may be a limiting factor in the continuous worldwide expansion of areas cropped to basil, but conventional chemical control of

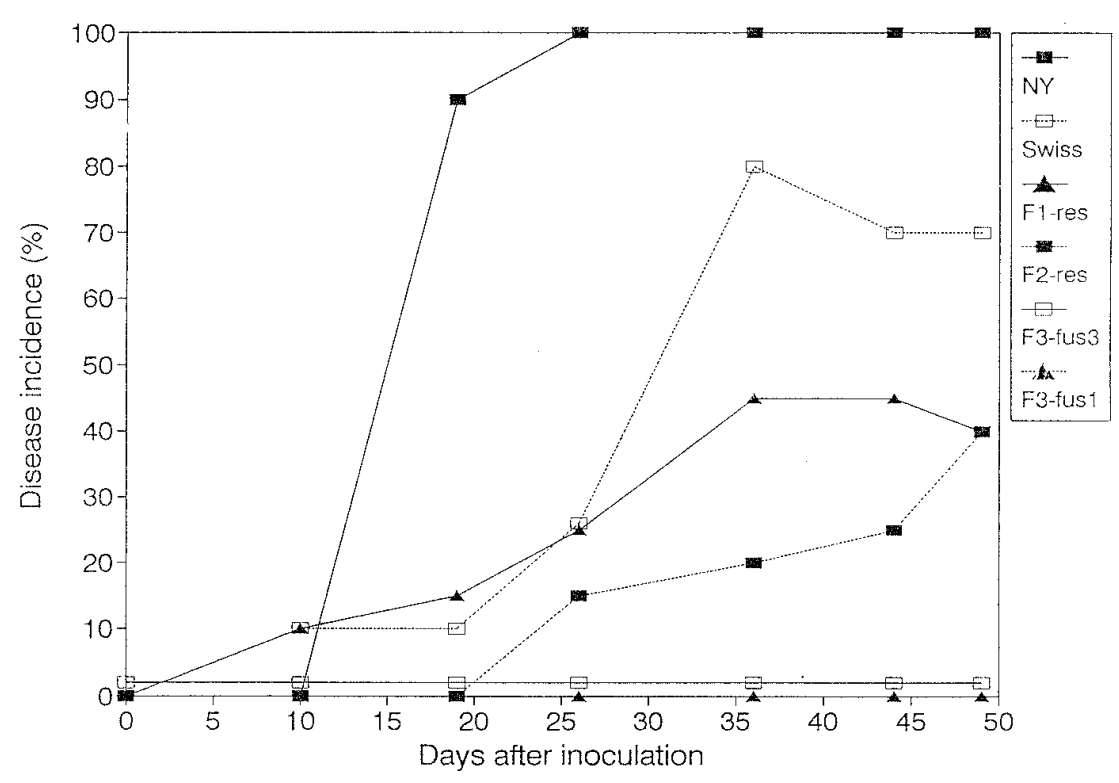

Fig. 1. Disease incidence in progenies of selected basil populations susceptible and resistant to Fusarium oxysporum f. sp. basilicum. Ten plants (four-leaf stage) of the following populationscommercial (NY) variety; resistant F1; resistant F2 (derived from $\mathrm{F} 1 \times \mathrm{F} 1$ crosses); and F3 populations derived from self crosses of plants resistant to FUS-1 (F3-Selec-1) or to FUS-3 (F3-Selec-3) were inoculated with a mixture of equal number of microconidia of isolates FUS-1 and FUS-3. Symptom development was rated for each plant using a 0 to $100 \%$ scale: $0=$ no symptoms; $25 \%=$ slight stunting or wilt; $50 \%=$ severe wilting and stunting; $100 \%=$ defoliation. The mean rating was calculated and recorded for each progeny, and disease incidence is expressed as the sum of these mean values. 
the disease by fungicides is ineffective and harmful to the environment. Identification and use of resistant germ plasm, as presented in the present report, is, therefore, the desirable strategy for better control of the disease. The host range of this disease has been reported to extend to sweet and lemon basil cultivars, but 6 other herbs in the family Lamiaceae were immune (7). This specificity of the pathogenic isolates of $F$. oxysporum has been designated as $F$. oxysporum f. sp. basilicum (4). Similarly, the present study shows that several isolates of $F$. oxysporum which originated in Israel in the summer of 1992 from stems of greenhouse-grown diseased sweet basil plants were pathogenic only to basil, and not to nine species representing Lamiaceae, Solanaceae, Cucurbitaceae, and Compositae (10).

The evaluation of basil and related herbs for their resistance to $F$. oxysporum, which was conducted in the United States, showed that all basil cultivars examined were susceptible to Fusarium wilt. However, a wide variation in reactions was observed in those growth chamber studies. This variation may be an artifact of the artificial inoculation system. On the other hand, the present data, obtained at Newe Ya'ar, indicate that artificial inoculations with isolates of $F$. oxysporum in the greenhouse were reliable for identification of resistant individuals among selected progenies, although higher disease incidence was observed under inoculation with a suspension of microconidia than from inoculation in the naturally infested soil. Interestingly, resistant germ plasm was identified in Israel in several plants of the susceptible commercial NY variety which had originally been introduced from the United States and acclimated in Israel as a leading fresh cultivar for export. This re-

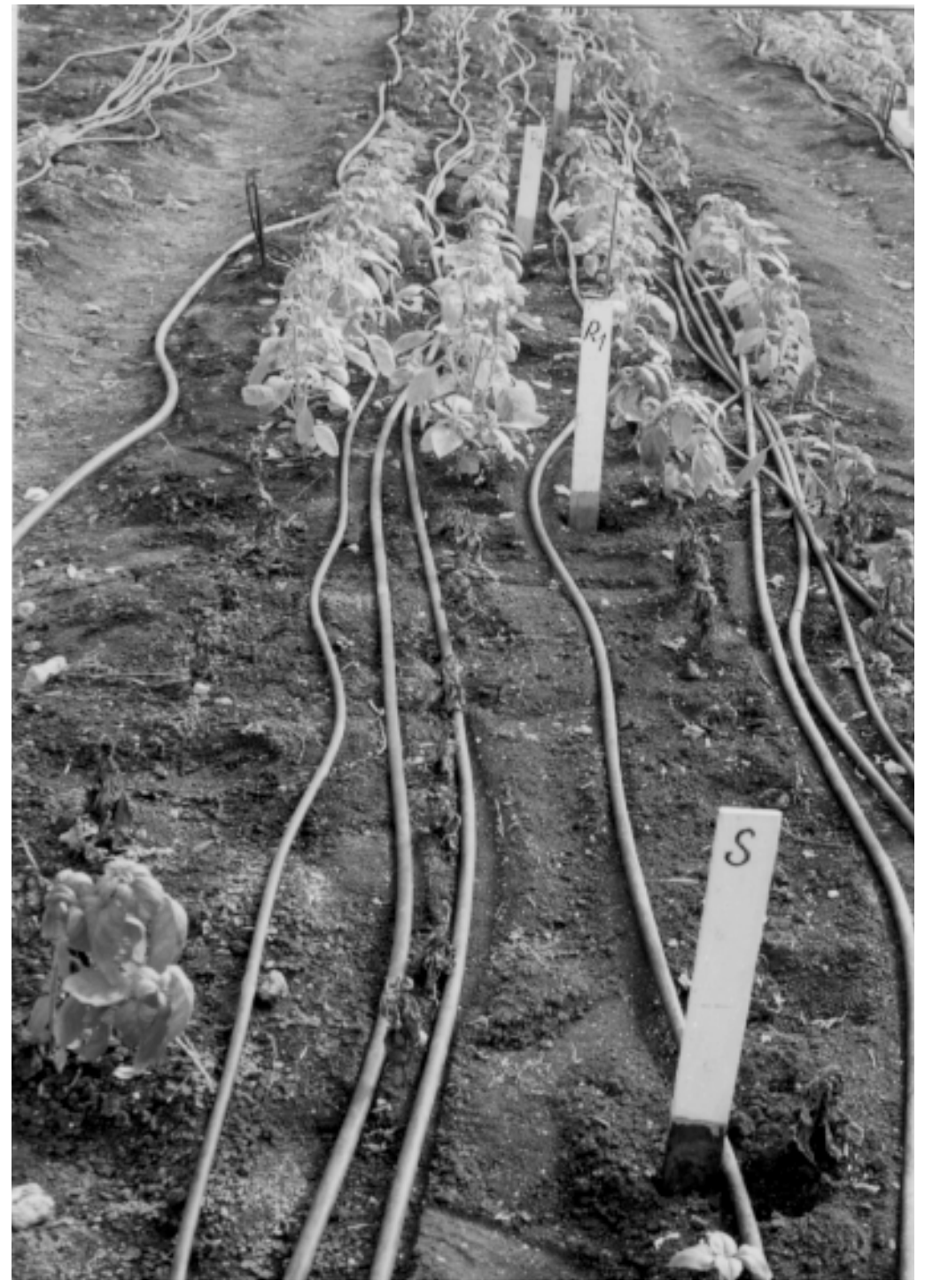

Fig. 2. Resistance of basil breeding lines to Fusarium wilt. Seeds of the susceptible Newe Ya'ar (NY) variety and of the resistant $\mathrm{F} 1$ and $\mathrm{F} 2$ progenies were planted in the greenhouse in naturally infested soil and transplanted into naturally infested field soil. $\mathrm{R}=$ Resistant F1 or F2; $\mathrm{S}=$ Susceptible NY variety. sistant germ plasm was further introduced into selected progenies which exhibit remarkable resistance to Fusarium wilt, and used as source for production of a favorable commercial cultivar (Table 2, Fig. 1 and 2). This cultivar has an agronomic advantage for export over the Swiss and Exotic cultivars. The resistance was apparent in highly infested soil in pots, in which repeated planting of basil was conducted under greenhouse conditions, and in the field. Development of an F3 generation of $100 \%$ symptomless basil plants means a remarkable increase in the number of resistant individuals from the origin $\mathrm{NY}$ cultivar through the F1, F2, and F3 generations. Additionally, a total number of 400 individuals obtained from 10 different F4 mother plants remained symptomless, while all 40 NY plants died after an artificial inoculation. This suggests that the resistance may be a single, dominant gene. Furthermore, this resistance is stable in the greenhouse and field in highly infested soil and is being successfully used for crosses to obtain a resistant cultivar of sweet basil (registered cv. "Nufar;" 1,11).

\section{ACKNOWLEDGMENTS}

This study was supported in part by the Department of Vegetables, Extension Services, Ministry of Agriculture, State of Israel, project No. 132-0944. We thank Doia Sa'adi, Lilia Frieman, and Anat Bar of the Newe Ya'ar Research Center for technical assistance.

\section{LITERATURE CITED}

1. Dudai, N., Reuveni, R., and Putievsky, E. 1995. "Nufar": A sweet basil variety, resistant to Fusarium wilt caused by Fusarium oxysporum f. sp. basilicum. Application for Registration No. 2376/95. Ministry of Agriculture, Israel Plant Breeders' Rights Council. Israel Plant Breeders' Gazette 42:2.

2. Elmer, W. H. 1995. Effect of compost soil amendments and foliar micronutrient applications on Fusarium wilt of basil. Biol. and Cult. Tests 10: 129

3. Elmer, W. H., Lacy, M. L., and Honma, S. 1986. Evaluations of celery germ plasm for resistance to Fusarium oxysporum f. sp. apii Race 2. Plant Dis. 70:416-619.

4. Elmer, W. H., Wick, R. L., and Haviland, P. 1994. Vegetative compatibility among isolates of Fusarium oxysporum f. sp. basilicum recovered from basil seeds and infected plants. Plant Dis. 78:789-791.

5. Gamliel, A., Katan, T., Ynis, H., and Katan, J. 1996. Fusarium wilt and crown rot of sweet basil: Involvement of soilborne and airborne inoculum. Phytopathology 86:56-62.

6. Grasso, D. S. 1975. Un avvizzimento del basilico de Fusarium oxysporum. Inf. Fitopatol. 25:5-7.

7. Keinath, A. P. 1994. Pathogenicity and host range of Fusarium oxysporum from sweet basil and evaluation of disease control methods. Plant Dis. 78:1211-1215.

8. Mercier, S., and Pionnat, J.-C. 1982. Presence en France de la fusariose vasculaire du basilic. C. R. Seances Acad. Agric. Fr. 68:416-419.

9. Reuveni, R., Dudai, N., and Putievsky, E. 1995. Identification of resistant germplasm of Ocimum basilicum resistant to Fusarium oxysporum. (Abstr.) Phytoparasitica 23:245.

10. Reuveni, R., Dudai, N., and Putievsky, E. 
1995. Germplasm of Ocimum basilicum resistant to Fusarium oxysporum. (Abstr.) Phytopathology 85:1178.

11. Reuveni, R., Dudai, N. and Putievsky E. 'NUFAR' - a sweet basil cultivar resistant to
Fusarium wilt caused by Fusarium oxysporum f. sp. basilicum. HortScience. In press.

12. Vergovskii, V. I. 1956 Some peculiarities in the presence of fusariosis in basil. Kratk. Otchet. Nauchno Issled. Vseoyus. Inst.
Maslichn. Efiromaslichn. Kult. 7:195-197 (Rev. Appl. Mycol. 38:613, 1959).

13. Wick, R. L., and Haviland, P. 1992. Occurrence of Fusarium wilt of basil in the United States. Plant Dis. 76:323. 